\title{
Effect of folic acid supplementation during pregnancy on growth and cognitive development of the offspring: a pilot follow-up investigation of children of FASSTT study participants
}

\author{
K. Pentieva ${ }^{1}$, C. McGarel $^{1}$, B. McNulty ${ }^{1}$, M. Ward, N. Elliott ${ }^{1}$, J. J. Strain ${ }^{1}$, M. D. Rollins ${ }^{2}$ \\ and H. McNulty ${ }^{1}$ \\ ${ }^{1}$ Northern Ireland Centre for Food and Health, University of Ulster, Coleraine, BT52 1SA and ${ }^{2}$ Northern Health and Social \\ Care Trust, Causeway Hospital, UK
}

It is well established that folic acid supplementation in the early stages of pregnancy can reduce the risk of neural tube defects and some other congenital malformations ${ }^{(1)}$. Observational research also suggests that maternal folate intake may have a long-term effect on the neurocognitive development of the offspring ${ }^{(2-3)}$, however, the evidence so far is inconclusive. The current study aimed to investigate the effect of folic acid supplementation during pregnancy on growth and cognitive development of young children.

Mother-child pairs $(n=39)$ were recruited from a previously conducted randomized control trial which investigated the effect of folic acid supplementation $(400 \mu \mathrm{g} /$ day) in the second and third trimester of pregnancy (FASSTT) study. Anthropometric measurements including height, weight, and waist circumference were taken in order to assess the physical development of the children at the age of 2.8 years. At the same time, the Bayley Scales of Infant and Toddler Development (BSITD), III edition ${ }^{(4)}$ was employed to evaluate the following five domains of child development: cognitive, receptive communication, expressive communication, fine and gross motor skills.

\begin{tabular}{lccc}
\hline $\begin{array}{l}\text { Developmental domains } \\
\text { assessed by BSITD }\end{array}$ & $\begin{array}{c}\text { Placebo }(n=16) \\
\text { mean }(95 \% \mathrm{CI})\end{array}$ & $\begin{array}{c}\text { Folic acid }(n=23) \\
\text { mean }(95 \% \mathrm{CI})\end{array}$ & $P$-value \\
\hline Cognitive & $9.57(8.60-10.06)$ & $10.65(9.66-11.09)$ & $0.044^{\mathrm{a}}$ \\
Receptive communication & $10.14(8.92-11.35)$ & $10.75(9.69-11.80)$ & 0.455 \\
Expressive communication & $10.64(9.52-11.88)$ & $10.47(9.52-11.53)$ & 0.825 \\
Fine motor skills & $9.61(8.62-10.71)$ & $10.28(9.35-11.29)$ & 0.365 \\
Gross motor skills & $8.29(7.34-9.35)$ & $8.60(7.74-9.57)$ & 0.656 \\
\hline Different superscript letters denote significant differences between the means as determined by ANCOVA, adjusted for
\end{tabular}

Children of mothers who received folic acid supplementation during the second and third trimester of pregnancy compared to those that did not showed significantly higher scores in the cognitive domain of infant development assessment after adjustment for maternal age, socio-economic factors and birth weight. The differences between the two groups in the other developmental domains of BSITD were not found to be significant. In addition, no significant differences in anthropometric measurements were observed between children born to mothers in the placebo and folic acid treatment groups (not shown). This pilot study suggests that folic acid supplement use during later pregnancy may confer an enhanced effect on the cognitive ability of young children. However, further research in a larger scale study is required to confirm these findings.

1. Czeizel AE and Dudas I (1992) N Engl J Med 327(26): 1832-5.

2. Murphy MM, Fernandez-Ballart J.D, Arija V et al. (2007) Clin Chem Lab Med 45(5), 83

3. Julvez J, Fortuny J, Mendez M et al. (2009) Paediatr Perinat Epidemiol 23, 199-206.

4. Bayley N (2006) Bayley Scales of Infant Development - Administration manual, $3^{\text {rd }}$ Edition, San Antonio: Harcourt Assessment. 